down." ${ }^{1}$ Health care, like politics, is local. Is it possible that what is cost-effective for one provider or consumer may not be true for another? How much of the problem is "provider" driven as compared with "consumer" driven, in which case the patient has little incentive to consider cost? Since medical egalitarianism does not endorse cost as the arbiter, who will make and enforce the decisions concerning cost? Is the provider free to consider scientific evidence when the trial bar can second-guess the process?

Although scientific advances look toward indi- vidualized medicine, it appears that cost-accounting exalts the cookbook approach. Since a new system should be tested first on a small scale, perhaps any testing of the new and better health care system should be conducted first on its strongest proponents, the Congress.

Robert C. Kane, M.D.

901 S. Tamiami Trail

Venice, FL

1. Weinstein MC, Skinner JA. Comparative effectiveness and health care spending - implications for reform. N Engl J Med 2010;362:460-5

\title{
Pasireotide Alone or with Cabergoline and Ketoconazole in Cushing's Disease
}

TO THE EDITOR: Cushing's disease, which is caused by an adrenocorticotropin-secreting pituitary adenoma, is associated with increased morbidity and mortality. ${ }^{1}$ Currently, there is no effective medical therapy for Cushing's disease. However, recent studies identified the somatostatin-receptor subtype 5 and dopamine-receptor subtype 2 as potential therapeutic targets in Cushing's disease. ${ }^{2}$

Pasireotide is a new somatostatin analogue that binds with high affinity to somatostatin-receptor subtypes 1,2 , and 3, and it especially has highaffinity binding to somatostatin-receptor subtype 5.3 In a recent 15 -day pilot study, pasireotide normalized the excretion of urinary free cortisol in $17 \%$ of patients with Cushing's disease. ${ }^{4} \mathrm{Ca}-$ bergoline, a dopamine-receptor subtype 2 agonist, can also normalize levels of urinary free cortisol in Cushing's disease, but this effect is often not maintained during prolonged treatment. ${ }^{5}$ Because the majority of adrenocorticotropin-secreting adenomas simultaneously express somatostatinreceptor subtype 5 and dopamine-receptor subtype $2,^{2}$ we hypothesized that pasireotide and dopamine-receptor subtype 2 agonists may have synergistic effects in the treatment of Cushing's disease. Finally, ketoconazole suppresses cortisol production at the adrenal level through inhibition of steroidogenic enzymes. ${ }^{1}$ In a prospective, openlabel, multicenter trial, we used a stepwise approach for the medical treatment of Cushing's disease, with pasireotide as the initial form of treatment and the sequential addition of cabergoline and low-dose ketoconazole.
Seventeen patients with Cushing's disease (mean age, 45.7 years; 13 women) were included in an 80-day trial with normalization of levels of urinary free cortisol as the main outcome measure. All patients began treatment with $100 \mu \mathrm{g}$ of pasireotide subcutaneously three times daily; this dose was increased to $250 \mu \mathrm{g}$ subcutaneously three times daily at day 15 if the level of urinary free cortisol had not normalized. At day 28, cabergoline was added to pasireotide at a dose of $0.5 \mathrm{mg}$ every other day (this dose was increased to $1.0 \mathrm{mg}$ every other day after 5 days and $1.5 \mathrm{mg}$ every other day after 10 days) if the level of urinary free cortisol remained elevated. If the level of urinary free cortisol had not normalized at day 60 , ketoconazole was added at a dose of $200 \mathrm{mg}$ thrice daily.

Pasireotide monotherapy induced sustained normalization of the level of urinary free cortisol in 5 of 17 patients (29\%) (Fig. 1A). The addition of cabergoline normalized urinary free cortisol values in an additional 4 of 17 patients (24\%). At day 60, a total of 8 of 17 patients (47\%) still had elevated urinary free cortisol levels with pasireotide-cabergoline combination therapy, although a trend toward normalization of levels of urinary free cortisol was observed in all but one patient, with a mean $( \pm \mathrm{SE})$ decrease of $48 \pm 6 \%$ in the level of urinary free cortisol. The addition of low-dose ketoconazole induced biochemical remission in six of these eight patients at day 80 , increasing the number of patients with a complete response to $88 \%$. Figure $1 \mathrm{~B}$ shows the effects of 28 days 
of pasireotide monotherapy in relation to the severity of hypercortisolism at baseline. In patients with mild hypercortisolism and those with severe hypercortisolism, significant reductions in the level of urinary free cortisol of up to $67 \%$ of the baseline value were observed.

Along with the normalization of the level of urinary free cortisol, the clinical features of Cushing's disease improved, including a decrease in body weight $(-2.4 \pm 0.9 \mathrm{~kg})$, waist circumference $(-4.2 \pm 1.3 \mathrm{~cm})$, systolic blood pressure $(-12 \pm 4 \mathrm{~mm} \mathrm{Hg})$, and diastolic blood pressure $(-8 \pm 3 \mathrm{~mm} \mathrm{Hg})$. Adverse events included disturbance of glucose homeostasis (glycated hemoglobin level, $5.8 \pm 0.2 \%$ to $6.7 \pm 0.3 \%$; $\mathrm{P}<0.01$ ) and a decrease in levels of serum type I insulinlike growth factor to below the lower limit of the normal range in 9 of 17 patients.

Thus, stepwise medical therapy for Cushing's disease with the use of three drugs that differentially target somatostatin-receptor subtype 5 and dopamine-receptor subtype 2 receptors in the adrenocorticotropin-secreting adenoma and steroidogenic enzymes in the adrenal cortex resulted in biochemical control in nearly $90 \%$ of patients.

Richard A. Feelders, M.D., Ph.D. Christiaan de Bruin, M.D., Ph.D.

Erasmus Medical Center

Rotterdam, the Netherlands

r.feelders@erasmusmc.nl

Alberto M. Pereira, M.D., Ph.D.

Johannes A. Romijn, M.D., Ph.D.

Leiden University Medical Center

Leiden, the Netherlands

Romana T. Netea-Maier, M.D., Ph.D.

Ad R. Hermus, M.D., Ph.D.

Radboud University Nijmegen Medical Center

Nijmegen, the Netherlands

Pierre M. Zelissen, M.D., Ph.D.

University Medical Center Utrecht

Utrecht, the Netherlands

Ramona van Heerebeek

Frank H. de Jong, Ph.D.

Aart-Jan van der Lely, M.D., Ph.D.

Wouter W. de Herder, M.D., Ph.D.

Leo J. Hofland, Ph.D.

Steven W. Lamberts, M.D., Ph.D.

Erasmus Medical Center

Rotterdam, the Netherlands

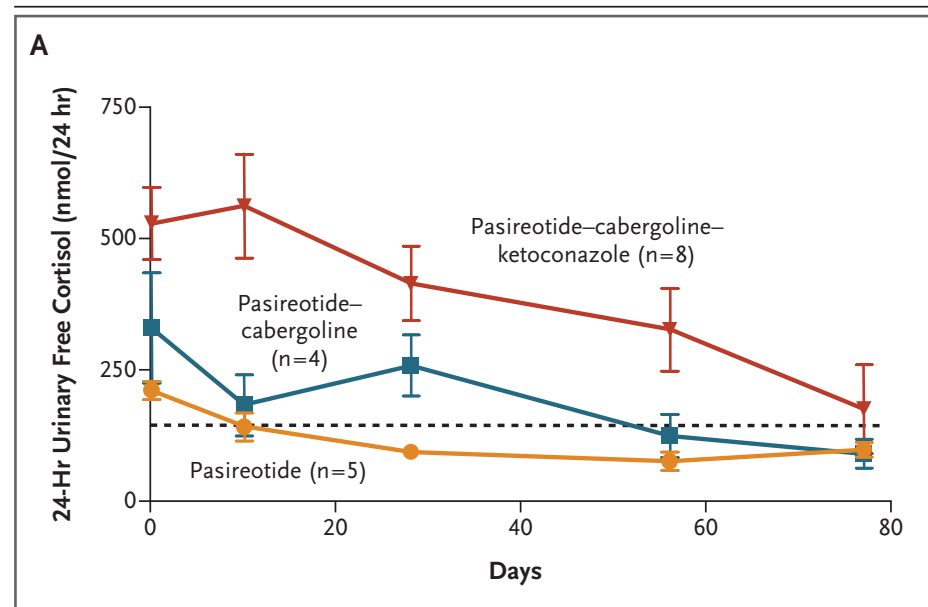

B

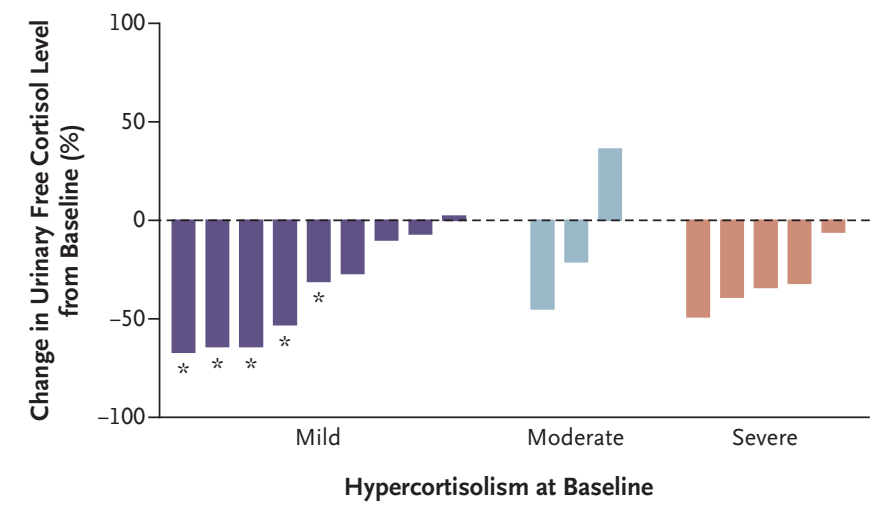

Figure 1. Levels of Urinary Free Cortisol after Treatment for Cushing's Disease.

Panel A shows mean levels of urinary free cortisol in five patients treated with pasireotide monotherapy, four patients treated with combination therapy with pasireotide plus cabergoline, and eight patients treated with pasireotide plus cabergoline and ketoconazole. Cabergoline was added to pasireotide if the level of urinary free cortisol had not normalized at day 28 . Ketoconazole was added to pasireotide and cabergoline at day 60 if the patient had persistent hypercortisolism. The upper limit of the normal range is indicated by the dashed line. I bars indicate the standard errors. Panel B shows the percent change from baseline in urinary free cortisol levels in all patients after pasireotide monotherapy at day 28 in relation to the severity of hypercortisolism before treatment. Hypercortisolism, measured according to the urinary free cortisol level, was classified as mild ( 1 to $<2$ times the upper limit of the normal range), moderate ( 2 to $<4$ times the upper limit of the normal range), or severe (4 to 6 times the upper limit of the normal range). In four patients, the urinary free cortisol level decreased by 50 to $75 \%$ from baseline, and in seven patients, this level decreased by 25 to $50 \%$ from baseline. Patients in whom urinary free cortisol levels normalized during pasireotide monotherapy had a baseline urinary free cortisol level of one to two times the upper limit of the normal range (bars with asterisks). 
Disclosure forms provided by the authors are available with the full text of this article at NEJM.org.

1. Newell-Price J, Bertagna X, Grossman AB, Nieman LK. Cushing's syndrome. Lancet 2006;367:1605-17.

2. de Bruin C, Pereira AM, Feelders RA, et al. Coexpression of dopamine and somatostatin receptor subtypes in corticotroph adenomas. J Clin Endocrinol Metab 2009;94:1118-24.

3. Schmid HA. Pasireotide (SOM230): development, mechanism of action and potential applications. Mol Cell Endocrinol 2008;286:69-74.
4. Boscaro M, Ludlam WH, Atkinson B, et al. Treatment of pituitary-dependent Cushing's disease with the multireceptor ligand somatostatin analog pasireotide (SOM230): a multicenter, phase II trial. J Clin Endocrinol Metab 2009;94:115-22.

5. Pivonello R, De Martino MC, Cappabianca P, et al. The medical treatment of Cushing's disease: effectiveness of chronic treatment with the dopamine agonist cabergoline in patients unsuccessfully treated by surgery. J Clin Endocrinol Metab 2009;94:223-30.

\section{Atypical Femoral Fractures and Bisphosphonate Use}

TO THE EDITOR: Since 2007, there have been several reports suggesting a potential association between the use of bisphosphonates and the occurrence of subtrochanteric or so-called atypical femoral fracture..$^{1-4}$ However, a recent registrybased cross-sectional study did not show a greater frequency of such fractures in patients receiving alendronate. ${ }^{5}$ Thus, the association between atypical femoral fractures and bisphosphonate use remains an open issue.

We reviewed 152 femoral fractures (not including hip) that occurred in 152 patients who were admitted to a tertiary center during a 60 -month period from June 2003 through May 2008. The mean $( \pm S D)$ age of the patients was $78 \pm 5$ years, and 132 of the patients were women. A senior orthopedic surgeon who was unaware of the patients' baseline characteristics and medication use reviewed the fracture radiographs of every patient in random sequence on two separate occasions (Cohen's $\kappa=0.8$ ), identifying those fractures that fit the criteria for an atypical fracture (i.e., a lateral transverse or $<30$-degree oblique fracture line in an area of cortical thickening with a medial unicortical beak), as described previously. ${ }^{3,4}$

Twenty of the 152 fractures were classified as atypical. After unblinding of the database, $17 \mathrm{pa}-$ tients in this group were found to be receiving current oral bisphosphonate treatment. Of these patients, 15 were taking alendronate (mean treatment duration, 5.1 years), and 2 were taking risedronate (mean treatment duration, 3 years). Of the 132 patients whose radiographs did not fulfill the criteria for atypical fracture, 2 patients $(1.5 \%)$ were taking alendronate, and 1 patient was taking risedronate $(0.8 \%)$, with mean treatment durations of 3.5 years and 1 year, respectively. The atypical fracture pattern appeared to be 96.7\% specific to patients receiving bisphosphonates.

Several additional risk factors were associated with atypical femur fracture. These included a history of low-energy fracture (odds ratio, 3.2; $95 \%$ confidence interval [CI], 2.1 to 17.1; $\mathrm{P}<0.001)$, the use of glucocorticoid therapy for more than 6 months (odds ratio, 5.2; 95\% CI, 1.3 to $31.0 ; \mathrm{P}=0.01$ ), active rheumatoid arthritis (odds ratio, 16.5; 95\% CI, 1.4 to 142.3 ; $\mathrm{P}<0.001$ ), and a level of serum 25-hydroxyvitamin $\mathrm{D}$ of less than $16 \mathrm{ng}$ per milliliter (40 nmol per liter) (odds ratio, 3.5; 95\% CI, 1.7 to 18.7; $\mathrm{P}<0.001$ ).

Although there is an association between atypical subtrochanteric femur fracture and oral bisphosphonate use, clinicians should remember that bisphosphonates significantly reduce the risk of fragility fractures in patients with osteoporosis and that overall the antifracture effects of bisphosphonates far outweigh their potential risks.

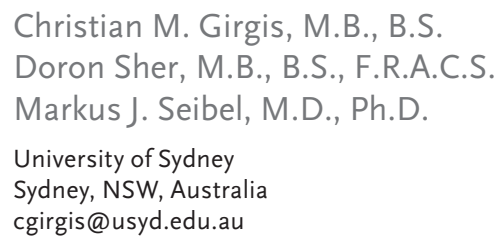

Christian M. Girgis, M.B., B.S.

Doron Sher, M.B., B.S., F.R.A.C.S. Markus J. Seibel, M.D., Ph.D.

\section{University of Sydney \\ Sydney, NSW, Australia \\ cgirgis@usyd.edu.au}

Disclosure forms provided by the authors are available with the full text of this letter at NEJM.org.

1. Lee P, van der Wall $\mathrm{H}$, Seibel MJ. Looking beyond low bone mineral density: multiple insufficiency fractures in a woman with post-menopausal osteoporosis on alendronate therapy. J Endocrinol Invest 2007;30:590-7.

2. Lee P, Seibel MJ. More on atypical fractures of the femoral diaphysis. N Engl J Med 2008;359:317.

3. Neviaser AS, Lane JM, Lenart BA, Edobor-Osula F, Lorich 